\title{
Effect of Cyclodextrins on Saccharide Sensing Function of a Fluorescent Phenylboronic Acid in Water
}

\author{
Rimiko Ozawa,* Takeshi Hashimoto,* Akiyo Yamauchi,** Iwao Suzuki,** Bradley D. Smith,*** \\ and Takashi HAYASHITA* ${ }^{*}$ \\ *Department of Chemistry, Faculty of Science and Technology, Sophia University, \\ Chiyoda, Tokyo 102-8554, Japan \\ **Graduate School of Pharmaceutical Science, Tohoku University, Sendai 980-8578, Japan \\ ***Department of Chemistry and Biochemistry, University of Notre Dame, Notre Dame, IN 46556, USA
}

\begin{abstract}
An inclusion complex consisting of a fluorescent phenylboronic acid (C1-APB) and $\beta$-cyclodextrin $(\beta$-CD) acts as a supramolecular saccharide sensor whose response mechanism is based on photoinduced electron transfer (PET). This study evaluated four kinds of cyclodextrins $\left(\alpha-\mathrm{CD}, \beta-\mathrm{CD}, \gamma-\mathrm{CD}\right.$, and $\left.\mathrm{NH}_{2}-\beta-\mathrm{CD}\right)$ by comparing their $\mathrm{pH}$ profiles, and confirmed that $\beta$-CD was the best host for C1-APB because the C1-APB/ $\beta$-CD complex exhibited high affinity for saccharides as well as high fluorescent recovery upon saccharide binding. An investigation of the $\beta$-CD concentration effect revealed the formation of a 1:1 inclusion complex of C1-APB with $\beta$-CD. The observed saccharide selectivity of the C1-APB $/ \beta$-CD complex is in the following order: D-fructose $\left(4039 \pm 69 \mathrm{M}^{-1}\right)>$ D-ribose $\left(1083 \pm 26 \mathrm{M}^{-1}\right)>\mathrm{L}^{-}$ arabinose $\left(474 \pm 11 \mathrm{M}^{-1}\right)>$ D-galactose $\left(318 \pm 3 \mathrm{M}^{-1}\right)>$ maltotoriose $\left(135 \pm 5 \mathrm{M}^{-1}\right)>$ D-glucose $\left(114 \pm 2 \mathrm{M}^{-1}\right)>\mathrm{maltose}^{-1}$ $\left(81 \pm 2 \mathrm{M}^{-1}\right)$. In addition to monomer emission, dimer emission from pyrene dimers was observed in the spectra for the C1-APB $/ \gamma$-CD complex, which allowed a ratiometric analysis. This study shows that the combination of a simple fluorescent probe, C1-APB, with various CDs diversifies the response systems for saccharide recognition.
\end{abstract}

(Received October 4, 2007; Accepted December 11, 2007; Published February 10, 2008)

\section{Introduction}

Sugars are essential biological molecules that play fundamental roles in metabolism and the maintenance of cell structure. They are also related to cell differentiation and immunity. ${ }^{1}$ Because of their important properties, researchers need simple methods that can quickly recognize sugars in aqueous solution. Enzymebased sensors are highly selective, but of limited use for continuous monitoring and in vivo analysis because of their poor stability and because they consume their substrate in the recognition process. Although chemosensors based on boronic acid are not as selective, they have attracted much attention because of their greater stability.,3 Phenylboronic acid can readily form stable cyclic esters with the diol moiety of sugars in water, ${ }^{4}$ and various types of the boronic acid chemosensors with response mechanism based on internal charge transfer (ICT) ${ }^{5-8}$ photoinduced electron transfer (PET), ${ }^{9-11}$ and fluorescent resonance energy transfer (FRET) ${ }^{12}$ have been developed.

The versatile designs of chemosensors based on supramolecular chemistry are another approach to construct novel sugar sensors. ${ }^{13-15}$ We reported that the complex consisting of the boronic acid fluorophore $(\mathbf{C 4}-\mathbf{C P B})$ and $\beta$ cyclodextrin $(\beta-\mathrm{CD})$ acts as a supramolecular saccharide sensor (Fig. 1). ${ }^{16}$ The $\beta$-CD solubilizes the water-insoluble C4-CPB by forming an inclusion complex. The fluorescence response of this complex is based on the PET mechanism. The inherent fluorescence of C4-CPB is quenched by the internal PET from pyrene to the trigonal form of phenylboronic acid, but

\footnotetext{
$\doteqdot$ To whom correspondence should be addressed.
}

saccharide binding converts the boronic acid to the tetrahedral boronate, thereby inhibiting PET quenching and increasing the fluorescence intensity. In a previous study, the spacer effect of the boronic acid probe was examined in detail by using the fluorophores C1-CPB, C4-CPB, and C1-APB (Fig. 1). We found that the $\mathbf{C 1 - A P B} / \beta-\mathrm{CD}$ complex was a desirable fluorescent chemosensor for saccharide recognition because of its high affinity to saccharides as well as its relatively high fluorescence recovery upon saccharide binding. Since C1-APB is more soluble than C1-CPB and C4-CPB, because of possessing an amide group, it can be dissolved in water without adding $\beta$-CD at the level for the fluorescent measurement. This makes a precise comparison of the $\mathrm{CD}$ effect feasible. In the present work, therefore, we focused on C1-APB/CD complexes, and investigated how the sensing function of C1-APB for saccharide recognition in water was affected by differences in

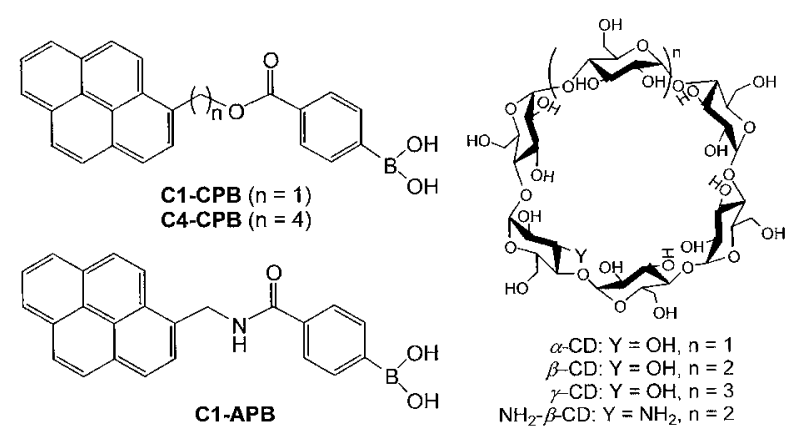

Fig. 1 Structure of fluorescent probes and CDs. 
the CD structure. Three of the CDs that we used are widely known ( $\alpha-\mathrm{CD}, \beta-\mathrm{CD}$, and $\gamma-\mathrm{CD}$, respectively), consisting of six, seven and eight glucose units. The diameter of the inner cavity of the $\mathrm{CD}$ increases with the number of glucose units, from 5.7 $\AA$ for $\alpha$-CD to $7.8 \AA$ for $\beta$-CD and to $9.5 \AA$ for $\gamma-\mathrm{CD} .{ }^{17}$ The other $\mathrm{CD}$ that we used was $\mathrm{NH}_{2}-\beta-\mathrm{CD}$, in which an amino group is substituted for one of the hydroxyls in $\beta$-CD (Fig. 1). We compared these CDs, and found that the differences in the cavity size as well as the substituent of the CDs affected the response systems for saccharide recognition.

\section{Experimental}

\section{Reagents}

2-(4-Phenylboronic acid)-1-pyrenemethamide (C1-APB) was synthesized by the following procedure. To a mixture of 4-(1pyrenyl) methylaminochloride (220 $\mathrm{mg}, 0.825 \mathrm{mmol})$, 2-(4carboxyphenyl)-1,3,2-dioxaborinane (155 mg, $0.825 \mathrm{mmol}$ ), triethylamine $(75 \mathrm{mg})$, and 1-hydroxy-7-azabenzotiazole (100 $\mathrm{mg}, 0.75 \mathrm{mmol})$ in dry $\mathrm{CH}_{2} \mathrm{Cl}_{2}$-DMF $(10: 1 \mathrm{v} / \mathrm{v}, 75 \mathrm{ml})$ was slowly added a solution of 1-(3-dimethylamino) propyl-3ethylcarbodiimide hydrochloride $(140 \mathrm{mg}, 0.75 \mathrm{mmol})$ in dry $\mathrm{CH}_{2} \mathrm{Cl}_{2}-\mathrm{DMF}(10: 1 \mathrm{v} / \mathrm{v}, 2 \mathrm{~mL})$ at $0^{\circ} \mathrm{C}$. Under dry $\mathrm{N}_{2}$, the reaction mixture was stirred at $0^{\circ} \mathrm{C}$ for $2 \mathrm{~h}$ and at room temperature for 2 days. The solvent was evaporated and $\mathrm{CH}_{2} \mathrm{Cl}_{2}$ $(20 \mathrm{~mL})$ was added. The desired product precipitated out and was filtered. Purification by column chromatography on silica gel with 3:1 ethyl acetate:hexane, and subsequently 1:4 methanol:chloroform as eluents gave $60 \mathrm{mg}(19.2 \%)$ of the product as an off-white solid. The solid was crystallized from ethanol. ${ }^{1} \mathrm{H}$ NMR $\left(\mathrm{CDCl}_{3}\right) \delta, 1.01(\mathrm{t}, 3 \mathrm{H}), 1.6(\mathrm{q}, 2 \mathrm{H}), 5.2(\mathrm{~s}$, 2H), 7.8 - $8.6(\mathrm{Ar}-\mathrm{H}, \mathrm{B}-\mathrm{OH}, 13 \mathrm{H}), 9.2(\mathrm{~s}, 1 \mathrm{H}) .{ }^{13} \mathrm{C}-\mathrm{NMR}$ $\left(\mathrm{CDCl}_{3}\right) \delta, 59,124,124.6,124.8,125.4,125.8,125.9,127$, $127.2,127.6,128,128.2,128.8,131.6,131.8,133.8,134.6$, 136.2. Positive-ion FAB-MS (glycerol matrix), $\mathrm{m} / \mathrm{z} 436$ $\left[\mathrm{M}+\mathrm{H}+\mathrm{gly}-2 \mathrm{H}_{2} \mathrm{O}\right]^{+}$.

$\gamma-\mathrm{CD}, \quad \alpha-\mathrm{CD}, \mathrm{D}(-)$-fructose, and other saccharides were obtained as special-grade reagents from Wako Pure Chemical Industries, Ltd. The first-reagent grade of $\beta$-CD (Wako Pure Chemical Industries, Ltd.) was recrystallized twice from water. $3 \mathrm{~A}$-amino-3A-deoxy-(2AS,3AS)- $\beta$-cyclodextrin $\quad\left(\mathrm{NH}_{2}-\beta\right.$-CD) was obtained from Tokyo Chemical Industry Co., Ltd. Water was doubly distilled and deionized by a Milli-Q water system (Millipore) before use. Other chemicals were of analytical reagent grade and were used as received.

\section{Apparatus}

Fluorescence spectra were measured by a Hitachi F-4500 fluorescence spectrometer (Hitachi, Ltd.) equipped with a 1.0$\mathrm{cm}$ quartz cell. The fluorescence emission from 350 to $550 \mathrm{~nm}$ was monitored at the excitation wavelength of $328 \mathrm{~nm}$ with a 5.0-nm slit width. The scan speed was $60 \mathrm{~nm} / \mathrm{min}$. All fluorescence spectra were obtained under an aerated condition. ${ }^{1} \mathrm{H}$ NMR spectra were obtained using a Varian INOVA 500 spectrometer (500 MHz, Varian, Inc.). Mass spectrometry was performed on a JEOL JMS-AX505HA spectrometer (JEOL Ltd.). All $\mathrm{pH}$ values were determined by a Horiba F-52 pH meter (HORIBA, Ltd.).

\section{Results and Discussion}

pH dependence of the fluorescence spectra

The fluorescence of the $\mathbf{C 1 - A P B / C D}$ complexes was

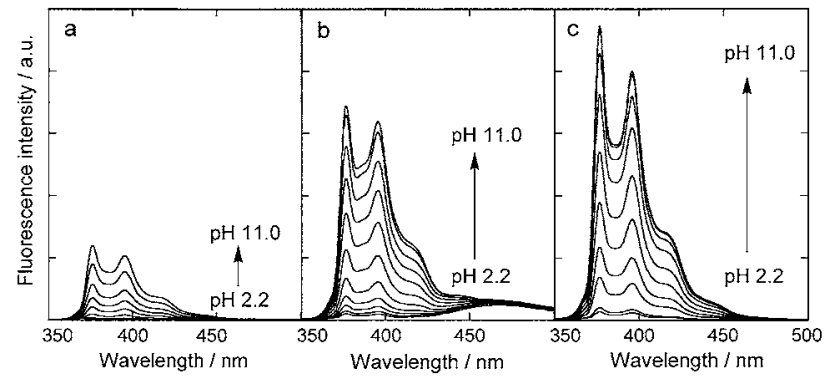

Fig. $2 \mathrm{pH}$ dependence of the fluorescence spectra for C1-APB without D-fructose, (a) C1-APB alone, (b) C1-APB $/ \gamma-\mathrm{CD}$, (c) C1$\mathbf{A P B} / \beta$-CD. $\quad[\mathbf{C} 1-\mathbf{A P B}]=1.0 \times 10^{-6} \mathrm{M}$ in $2 \%$ DMSO- $98 \%$ water (v/v) containing 0.0 or $5.0 \mathrm{mM} \mathrm{CD}, \mathrm{pH}$ at $25^{\circ} \mathrm{C}$ adjusted with $0.01 \mathrm{M}$ phosphate buffer, $I=0.1 \mathrm{M}$ with $\mathrm{NaCl}, \lambda_{\mathrm{ex}}=328 \mathrm{~nm}$.

examined under different $\mathrm{pH}$ conditions. As shown in Fig. 2a, the fluorescence intensity of C1-APB alone increases as the $\mathrm{pH}$ increases from 2.2 to 11.0. The presence of $5 \mathrm{mM}\left(\mathrm{M}: \mathrm{mol} \mathrm{dm}{ }^{-3}\right)$ $\gamma-\mathrm{CD}$ (Fig. 2b) or $\beta$-CD (Fig. 2c), however, resulted in far more intense fluorescence at any $\mathrm{pH}$. The maximum fluorescence intensity of the C1-APB/ $\mathrm{NH}_{2}-\beta-\mathrm{CD}$ complex was about $50 \%$ lower than that of the $\mathbf{C 1 - A P B} / \beta-\mathrm{CD}$ complex under basic conditions, and the fluorescence spectra of the C1-APB $/ \alpha-\mathrm{CD}$ complex were the almost same as those of the C1-APB alone (results not shown). As a result, $\beta$-CD resulted in the strongest fluorescence response among these four kinds of CDs.

The corresponding fluorescence spectra were also measured in the presence of $30 \mathrm{mM}$ D-fructose. Although similar spectra were obtained for each $\mathrm{CD}$, the $\mathrm{pH}$ profiles were clearly different. The maximum fluorescence intensity of the C1APB/ $\beta$-CD complex was measured at $377 \mathrm{~nm}$ (Fig. 2c), and the $I_{377}$ values are plotted against $\mathrm{pH}$ in Fig. $3 \mathrm{c}$. The solid lines of Fig. $3 \mathrm{c}$ were obtained from the theoretical calculation, ${ }^{16}$ and $\mathrm{p} K_{\mathrm{a}}$ values were determined by nonlinear curve-fitting. The $\mathrm{p} K_{\mathrm{a}}$ without D-fructose is 8.07 , but the apparent $\mathrm{p} K_{\mathrm{a}}\left(\mathrm{p} K_{\mathrm{a}}^{\mathrm{app}}\right)$ with Dfructose is 6.01. This apparent $\mathrm{p} K_{\mathrm{a}}$ shift $\left(\Delta \mathrm{p} K_{\mathrm{a}}^{\mathrm{app}}\right)$ enables the C1-APB $/ \beta$-CD complex to recognize $D$-fructose under neutral conditions.

The equilibria in Scheme 1 show the proton-dissociation and saccharide-binding equilibria in water. The PET-based fluorescence change without D-fructose occurs upon conversion from the trigonal form under acidic conditions to the tetrahedral form under basic conditions. The presence of D-fructose shifts the apparent $\mathrm{p} K_{\mathrm{a}}$ lower, which suggests that the tetrahedral form is produced at a lower $\mathrm{pH}$ because boronic acid and saccharides form anionic esters.

The $I_{377} v s . \mathrm{pH}$ profiles of C1-APB alone (Fig. 3a), the C1$\mathbf{A P B} / \alpha-\mathrm{CD}$ complex (Fig. $3 \mathrm{~d}$ ) and the C1-APB $/ \mathrm{NH}_{2}-\beta-\mathrm{CD}$ complex (Fig. 3e) reveal two $\mathrm{p} K_{\mathrm{a}}$ 's. The lower $\mathrm{p} K_{\mathrm{a}}\left(\mathrm{p} K_{\mathrm{a} 1}\right)$ is close to that of the C1-APB $/ \beta$-CD complex, suggesting that the $\mathrm{p} K_{\mathrm{a} 1}$ is induced by the proton dissociation of boronic acid in the same way as in Scheme 1. The higher $\mathrm{p} K_{\mathrm{a}}\left(\mathrm{p} K_{\mathrm{a} 2}\right)$ seems to be caused by proton dissociation of the amide group, which should have a higher $\mathrm{p} K_{\mathrm{a}}$ than that of the boronic acid. The $\mathbf{C 1 - A P B} / \beta$ $\mathrm{CD}$ complex and the $\mathbf{C 1 - A P B} / \gamma-\mathrm{CD}$ complex display only simple one- $\mathrm{p} K_{\mathrm{a}} \mathrm{pH}$ profiles (Figs. $3 \mathrm{~b}$ and $3 \mathrm{c}$ ) indicating that the $\mathrm{p} K_{\mathrm{a}}$ of the amide group increased in the hydrophobic cavity of $\mathrm{CD}$, and the $\mathrm{p} K_{\mathrm{a} 2}$ was not observed under $\mathrm{pH} 11$ (Table 1 ).

The formation of an inclusion complex of C1-APB with $\beta$-CD or $\gamma-\mathrm{CD}$ increases the fluorescence intensity above that of $\mathbf{C 1}$ APB alone at any $\mathrm{pH}$. In general, the fluorescence intensity increases in a hydrophobic environment, like that in the $\mathrm{CD}$ 
Table 1 Binding constants for D-fructose calculated from $\mathrm{p} K_{\mathrm{a}} \mathrm{s}$ witho ut D-fructose and $\mathrm{p} K_{\mathrm{a}}^{\text {app's }}$ with D-fructose

\begin{tabular}{|c|c|c|c|c|c|c|}
\hline \multirow{2}{*}{$\mathrm{CD}$} & \multicolumn{2}{|c|}{ Without D-fructose } & \multicolumn{2}{|c|}{ With $30 \mathrm{mM}$ D-fructose } & \multirow{2}{*}{$\Delta \mathrm{p} K_{\mathrm{a} 1}^{\mathrm{app}}$} & \multirow{2}{*}{$K_{\mathrm{LS}} / \mathrm{M}^{-}$} \\
\hline & $\mathrm{p} K_{\mathrm{al}}$ & $\mathrm{p} K_{\mathrm{a} 2}$ & $\mathrm{p} K_{\mathrm{a} 1}^{\mathrm{app}}$ & $\mathrm{p} K_{\mathrm{a} 2}^{\mathrm{app}}$ & & \\
\hline None & $8.09 \pm 0.03$ & $10.15 \pm 0.01$ & $6.59 \pm 0.04$ & $9.12 \pm 0.05$ & $1.50 \pm 0.07$ & 1000 \\
\hline$\alpha-\mathrm{CD}$ & $8.18 \pm 0.02^{\mathrm{a}}$ & $10.11 \pm 0.02^{\mathrm{a}}$ & $6.51 \pm 0.05^{\mathrm{a}}$ & $9.35 \pm 0.05^{\mathrm{a}}$ & $1.67 \pm 0.07$ & $1500^{\mathrm{b}}$ \\
\hline$\gamma-\mathrm{CD}$ & $7.85 \pm 0.01^{\mathrm{a}}$ & - & $5.82 \pm 0.01^{\mathrm{a}}$ & - & $2.03 \pm 0.01$ & $3600^{\mathrm{b}}$ \\
\hline$\beta-\mathrm{CD}$ & $8.07 \pm 0.01^{\mathrm{a}}$ & - & $6.01 \pm 0.01^{\mathrm{a}}$ & - & $2.06 \pm 0.02$ & $3800^{\mathrm{b}}$ \\
\hline $\mathrm{NH}_{2}-\beta-\mathrm{CD}$ & $8.11 \pm 0.01^{\mathrm{a}}$ & $10.70 \pm 0.01^{\mathrm{a}}$ & $6.01 \pm 0.02^{\mathrm{a}}$ & $8.94 \pm 0.03^{\mathrm{a}}$ & $2.11 \pm 0.03$ & $4200^{\mathrm{b}}$ \\
\hline
\end{tabular}

a. Conditional apparent acidity constants in the presence of $5.0 \mathrm{mM} \mathrm{CDs}$. b. Conditional binding constants in the presence of $5.0 \mathrm{mM}$ CDs.
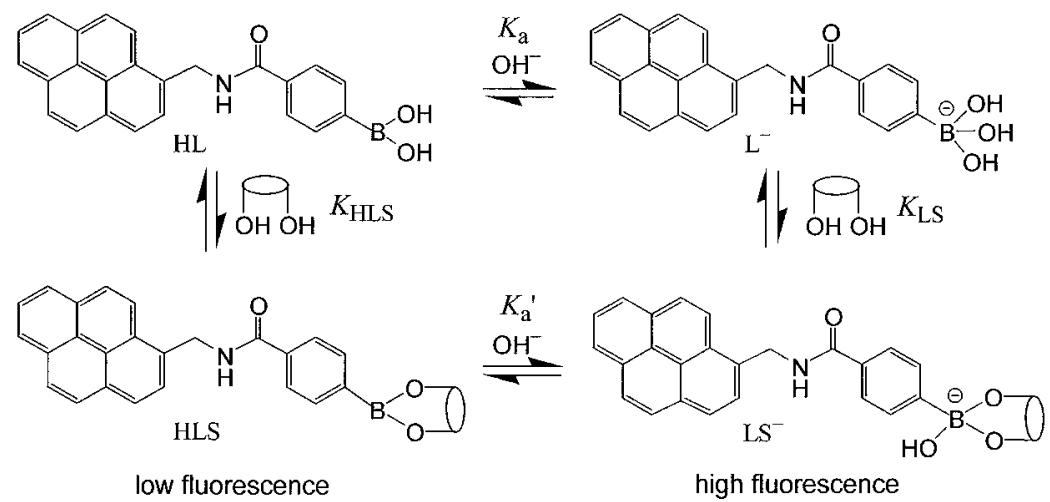

Scheme 1 Proton-dissociation and saccharide-binding equilibria of C1-APB in aqueous solution.
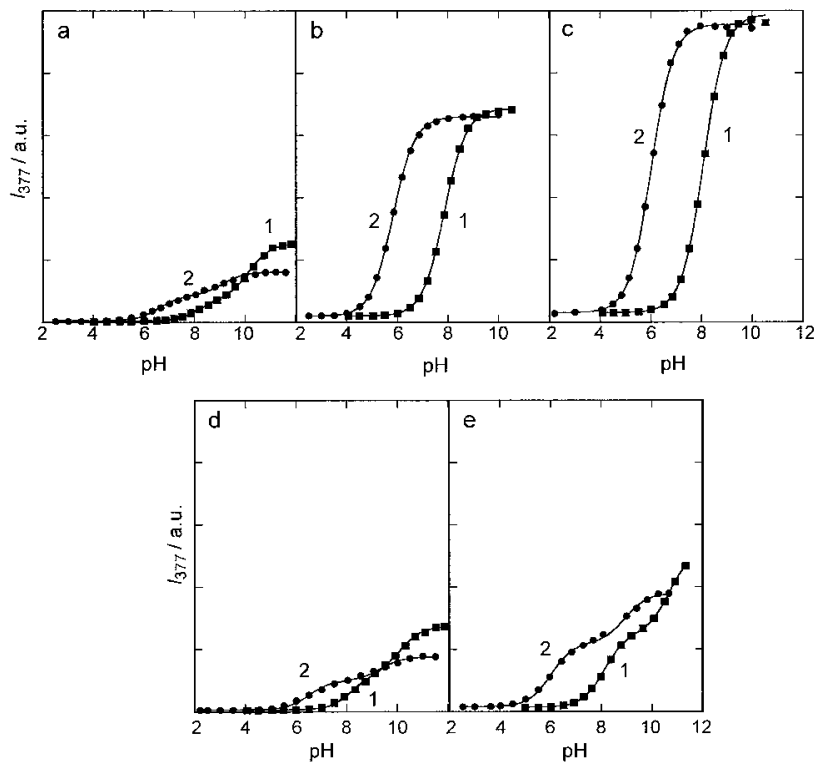

Fig. $3 \quad I_{377}$ versus $\mathrm{pH}$ profiles for $\mathbf{C 1 - A P B} / \mathrm{CD}$ with and without Dfructose. (a) C1-APB alone, (b) C1-APB $/ \gamma-\mathrm{CD}$, (c) $\mathbf{C} 1-\mathrm{APB} / \beta-\mathrm{CD}$, (d) $\mathbf{C 1 - A P B} / \alpha$-CD, (e) C1-APB $/ \mathrm{NH}_{2}-\beta$-CD. $[\mathbf{C 1}-\mathbf{A P B}]=1.0 \times 10^{-6}$ $\mathrm{M}$ in $2 \%$ DMSO-98\% water (v/v) containing 0.0 or $5.0 \mathrm{mM} \mathrm{CD}, \mathrm{pH}$ at $25^{\circ} \mathrm{C}$ adjusted with $0.01 \mathrm{M}$ phosphate buffer, $I=0.1 \mathrm{M}$ with $\mathrm{NaCl}$, $\lambda_{\mathrm{ex}}=328 \mathrm{~nm}$. (1) $[$ fructose $]=0 \mathrm{mM}$, (2) [fructose $]=30 \mathrm{mM}$.

cavity. In addition to this, the formation of the inclusion complex of C1-APB with the suitable size of CDs restricts the molecular motion of C1-APB and inhibits the radiationless transition process. These phenomena efficiently increase the fluorescence quantum yield.
$\beta$-CD is large enough to enclose the pyrene moiety of $\mathbf{C 1 -}$ APB and produces the greatest fluorescence intensity whereas $\alpha$-CD is too small to enclose C1-APB and $\gamma-\mathrm{CD}$ is too large to fit a single C1-APB molecule. On the other hand, $\gamma$-CD can incorporate two pyrene moieties, as reported in earlier studies. ${ }^{18,19}$ In the fluorescence spectra of the C1-APB $/ \gamma-C D$ complex, a slight level of dimer emission is evident at longer wavelengths (Fig. 2b). The formation of pyrene dimers decreases the monomer emission, and hence the maximum fluorescence intensity $\left(I_{377}\right)$ of the $\mathbf{C 1 - A P B} / \gamma-\mathrm{CD}$ complex is less than that of the $\mathbf{C 1 - A P B} / \beta-\mathrm{CD}$ complex. The $I_{377} v s . \mathrm{pH}$ profiles of the C1-APB/ $/ \mathrm{NH}_{2}-\beta-\mathrm{CD}$ complex (Fig. 3e) are quite different from those of the C1-APB $/ \beta$-CD complex (Fig. 3c). The amino group $\left(-\mathrm{NH}_{2}\right)$ on the $\beta$-CD rim appears to inhibit the formation of an inclusion complex with the pyrene moiety of C1-APB. It should be noted, however, that the fluorescence intensity of the $\mathbf{C 1 - A P B} / \mathrm{NH}_{2}-\beta-\mathrm{CD}$ complex is higher than that of C1-APB alone.

The $\mathrm{p} K_{\mathrm{a}}^{\mathrm{app}}$ shift of the $\mathrm{pH}$ profiles with and without D-fructose can be used for determining the conditional binding constants of the C1-APB/CD complexes for D-fructose. It is noted that the equilibria shown in Scheme 1 should include the inclusion complex formation of C1-APB with CDs. However, the equilibrium analysis including all the system is too complicated to evaluate the binding constants of $\mathbf{C 1 - A P B / C D}$ complexes for saccharides. Thus, for simplicity, we used a conditional equilibrium of C1-APB with saccharide at the fixed CD concentration. As we reported earlier, ${ }^{16}$ the conditional binding constant $\left(K_{\mathrm{LS}}\right)$ at the fixed CD condition is expressed as

$$
\Delta \mathrm{p} K_{\mathrm{a}}^{\mathrm{app}}=\log \left(1+K_{\mathrm{LS}}[\mathrm{S}]\right),
$$

where $[\mathrm{S}]$ is the saccharide concentration. The results are summarized in Table 1. The larger $\Delta \mathrm{p} K_{\mathrm{a}}^{\text {app }}$ represents the higher 


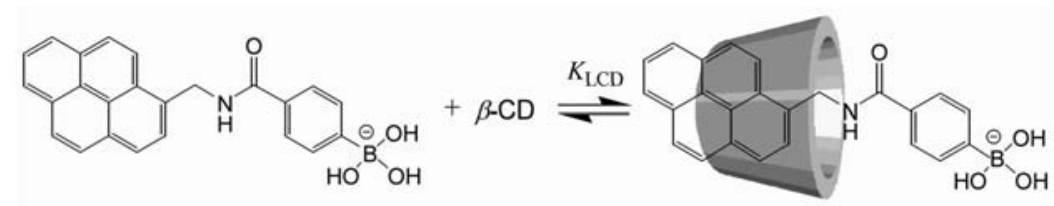

Scheme 2 Equilibrium of 1:1 inclusion complex of C1-APB with $\beta$-CD.

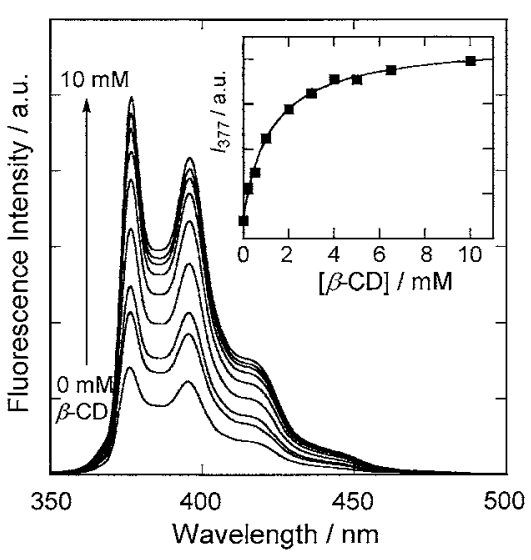

Fig. 4 Effect of the $\beta$-CD concentration on the fluorescence spectra and the fluorescence intensity at $377 \mathrm{~nm}$ (inset figure) for C1-APB without saccharide at $\mathrm{pH}$ 9.2. $[\mathbf{C 1 - A P B}]=1 \times 10^{-6} \mathrm{M}$ in $2 \%$ DMSO- $98 \%$ water (v/v), $\mathrm{pH}$ at $25^{\circ} \mathrm{C}$ adjusted to 9.2 with $0.01 \mathrm{M}$ sodium hydrogencarbonate, $I=0.1 \mathrm{M}$ with $\mathrm{NaCl}, \lambda_{\mathrm{ex}}=328 \mathrm{~nm}$.

binding ability. The conditional binding constant of the C1APB $/ \beta$-CD complex is 3.8 times higher than that of $\mathbf{C 1 - A P B}$ alone, suggesting that there is an interaction between a hydroxyl group of $\beta$-CD and the boronic acid ester, and this hydrogen bond makes the boronic acid ester formation more stable. The C1-APB $/ \gamma-C D$ complex showed the lowest $\mathrm{p} K_{\mathrm{a}}$ in the absence of D-fructose (7.85). Although the reason is unclear at present, the hydrogen bonding of the boronic acid with the hydroxyl group of $\gamma-\mathrm{CD}$, or the formation of C1-APB dimers may affect the proton dissociation. The $\mathbf{C} \mathbf{1}-\mathbf{A P B} / \alpha-\mathrm{CD}$ complex, in contrast, showed the highest $\mathrm{p} K_{\mathrm{a}}$ in the absence of D-fructose (8.18). We suspect that this is because the boronic acid moiety of C1-APB interacted with the $\alpha$-CD cavity. It is reasonable that the $\mathrm{p} K_{\mathrm{a}}$ of boronic acid exhibited a slight increase in the narrowest $\mathrm{CD}$ cavity because of the hydrophobic effect. ${ }^{20}$ The conditional binding constant of the $\mathbf{C} 1-\mathbf{A P B} / \mathrm{NH}_{2}-\beta-\mathrm{CD}$ complex is comparable to that of the $\mathbf{C 1 - A P B} / \beta$-CD complex, although the fluorescence intensity is lower than that of the C1APB $/ \beta$-CD complex. Since the amino group on the $\beta$-CD rim is protonated under acidic and neutral conditions, ${ }^{21}$ the electrostatic interaction stabilizing the anionic boronate ester should be taken into consideration.

Overall, of these four CDs, $\beta$-CD is the best host for C1-APB. The C1-APB $/ \beta$-CD complex showed the largest fluorescence intensity change as well as a large $\mathrm{p} K_{\mathrm{a}}^{\mathrm{app}}$ shift in the presence of D-fructose, evidence of a high conditional binding constant with D-fructose.

\section{Effect of $\beta$-CD concentration}

Because of the small fluorescence intensity change for C1APB under acidic conditions, the effect of $\beta$-CD on the fluorescence intensity of C1-APB without D-fructose was investigated at $\mathrm{pH} 9.2$, at which the boronate anion $\left(\mathrm{L}^{-}\right)$is the main species, so as to elucidate an inclusion ability (Scheme 2). The fluorescence intensity increased drastically as the $\beta$-CD concentration increased (Fig. 4). Based on the 1:1 inclusion complex formation for C1-APB $\left(\mathrm{L}^{-}\right)$and $\mathrm{CD}$, the relationship between fluorescence intensity $(I)$ and the $\mathrm{CD}$ concentration $[C D]$ can be expressed by the following equations:

$$
\begin{aligned}
& \mathrm{L}^{-}+\mathrm{CD} \rightleftharpoons \mathrm{L}^{-} \cdot \mathrm{CD}, \\
& K_{\mathrm{LCD}}=\frac{\left[\mathrm{L}^{-} \cdot \mathrm{CD}\right]}{\left[\mathrm{L}^{-}\right][\mathrm{CD}]},
\end{aligned}
$$

and

$$
I=\frac{\beta[\mathrm{L}]_{\mathrm{t}}\left(\phi_{\mathrm{L}}+\phi_{\mathrm{LCD}} K_{\mathrm{LCD}}[\mathrm{CD}]\right)}{1+K_{\mathrm{LCD}}[\mathrm{CD}]}
$$

where $\phi$ is the fluorescence quantum yield for the corresponding chemical species, $\beta$ is a constant proportional to the intensity of the excitation light and the molar extinction coefficient of $\mathbf{C 1 -}$ APB, and $[\mathrm{L}]_{\mathrm{t}}$ is the total concentration of C1-APB. The fluorescence intensity changes at $377 \mathrm{~nm}$ are shown in the inset of Fig. 4 as a function of CD concentration. The observed results were well fitted with Eq. (4) (solid line), and the binding constant $\left(K_{\mathrm{LCD}}\right)$ of $\mathbf{C 1}$-APB with $\beta$-CD was calculated from the theoretical curve to be $820 \pm 60 \mathrm{M}^{-1}$. The binding constant was also calculated using the Benesi-Hildebrand method, ${ }^{22}$ and both results were in good agreement. This strongly supports 1:1 inclusion complex formation of $\mathbf{C 1 - A P B}$ with $\beta$-CD.

\section{Selectivity of $\mathbf{C 1}-\mathbf{A P B} / \boldsymbol{\beta}-\mathrm{CD}$ for saccharides}

The precise values of the conditional binding constants $\left(K_{\mathrm{LS}}\right)$ in the presence of $5 \mathrm{mM} \beta-\mathrm{CD}$ can be obtained from the saccharide titration analysis by using the $\mathrm{p} K_{\mathrm{a}}$ value in the absence of saccharide. ${ }^{16}$ Thereby, the effect of the concentration of seven kinds of saccharides was examined at $\mathrm{pH}$ 7.1 (Fig. 5). The fluorescence intensity of the $\mathbf{C 1 - A P B} / \beta-\mathrm{CD}$ complex increases upon the addition of saccharides. The binding constant at a given $\mathrm{pH}$ is readily determined by nonlinear curve-fitting analysis of the following equation giving fluorescence intensity $(I)$ as a function of saccharide concentration ([S]):

$$
I=\frac{\beta[\mathrm{L}]_{t}\left(\phi_{\mathrm{HL}}+\phi_{\mathrm{L}} \frac{K_{\mathrm{a}}}{\left[\mathrm{H}^{+}\right]}\left(1+K_{\mathrm{LS}}[\mathrm{S}]\right)\right)}{1+\frac{K_{\mathrm{a}}}{\left[\mathrm{H}^{+}\right]}\left(1+K_{\mathrm{LS}}[\mathrm{S}]\right)} .
$$

As shown in Fig. 5, the observed fluorescence changes against the saccharide concentration are well fitted by Eq. (5) (solid lines). In the order whose conditional $K_{\mathrm{LS}}$ value is high among monosaccharides, D-fructose $\left(4039 \pm 69 \mathrm{M}^{-1}\right)>$ D-ribose $(1083$ $\left.\pm 26 \mathrm{M}^{-1}\right)>$ L-arabinose $\left(474 \pm 11 \mathrm{M}^{-1}\right)>$ D-galactose $(318 \pm 3$ $\left.\mathrm{M}^{-1}\right)>$ D-glucose $\left(114 \pm 2 \mathrm{M}^{-1}\right)$. These results follow the wellknown selectivity order of phenylboronic acid towards saccharides. $^{2,4}$ The conditional binding constants for maltose and maltotriose were also calculated as $81 \pm 2$ and $135 \pm 5 \mathrm{M}^{-1}$, 


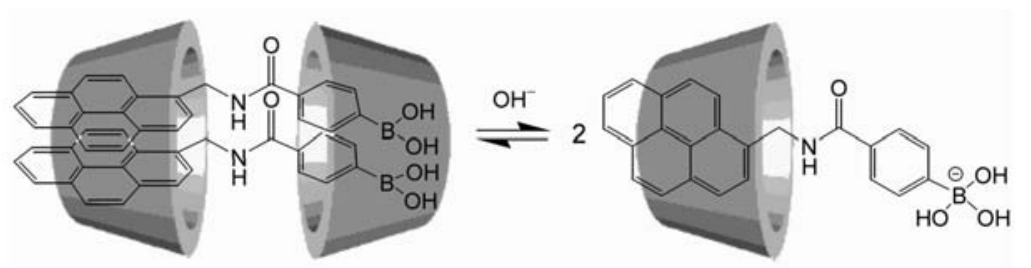

Scheme 3 Equilibria of 2:2 and 1:1 inclusion complex of C1-APB with $\gamma-\mathrm{CD}$.

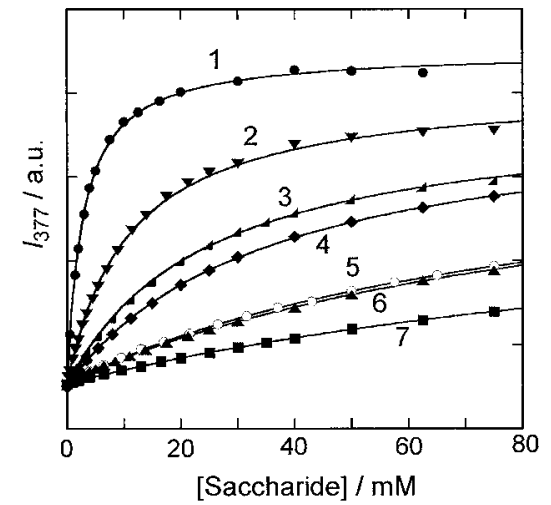

Fig. 5 Effect of the saccharide concentration on the fluorescent response of $\mathbf{C 1 - A P B} / \beta-\mathrm{CD}$ at $\mathrm{pH}$ 7.1. $[\mathbf{C 1}-\mathbf{A P B}]=1.0 \times 10^{-6} \mathrm{M}$ in $2 \%$ DMSO-98\% water (v/v) containing $5.0 \mathrm{mM} \beta-\mathrm{CD}, \mathrm{pH}$ at $25^{\circ} \mathrm{C}$ adjusted to 7.1 with $0.01 \mathrm{M}$ phosphate buffer, $I=0.1 \mathrm{M}$ with $\mathrm{NaCl}$, $\lambda_{\mathrm{ex}}=328 \mathrm{~nm}$. (1) D-Fructose, (2) D-ribose, (3) L-arabinose, (4) Dgalactose, (5) maltotriose, (6) D-glucose, (7) maltose.

respectively. The conditional binding constants of the C1APB $/ \beta$-CD complex for D-fructose were obtained in two ways: from $\Delta \mathrm{p} K_{\mathrm{a}}^{\mathrm{app}}\left(3800 \mathrm{M}^{-1}\right.$ in Table 1$)$ and from the titration curve of D-fructose $\left(4039 \mathrm{M}^{-1}\right)$. The difference between these results is within the experimental error.

\section{Ratiometric response}

The fluorescence spectra of the $\mathbf{C 1 - A P B} / \gamma-\mathrm{CD}$ complex display a slight dimer emission at longer wavelengths (Fig. 2b), but those of C1-APB alone and of the other C1-APB/CD complexes do not. It has been reported that pyrenes form a $2: 2$ inclusion complex with $\gamma-\mathrm{CD}$ as a barrel-type complex (a headto-head complex with secondary hydroxyl sides facing each other) and show dimer emission. ${ }^{23}$ A similar 2:2 inclusion complex of C1-APB with $\gamma-\mathrm{CD}$ is expected (Scheme 3). The possibility of a $2: 1$ inclusion complex formation should not be excluded, though. If the formation of boronate ester anions in a 2:2 (or a 2:1) inclusion complex causes the electrostatic repulsion and forms a 1:1 inclusion complex, the ratio of dimer $\left(I_{465}\right)$ /monomer emission $\left(I_{377}\right)$ would be used for the ratiometric sensing of saccharides. ${ }^{24}$ The effect of the $\gamma$-CD concentration on the fluorescence response of the $\mathbf{C 1 - A P B} / \gamma-\mathrm{CD}$ complex was therefore examined under basic and neutral conditions (Inset in Fig. 6). As expected, strong dimer emission was found to appear for the C1-APB $/ \gamma-\mathrm{CD}$ complex when the $\gamma-\mathrm{CD}$ concentration was increased, and the highest dimer/monomer ratio was obtained with $15 \mathrm{mM} \gamma-\mathrm{CD}$ at neutral $\mathrm{pH}$. The spectra of the C1-APB $/ \gamma-\mathrm{CD}$ inclusion complex formed with $15 \mathrm{mM} \gamma$ $\mathrm{CD}$ under neutral and basic conditions are shown in Fig. 6. It is evident that the high dimer emission was seen only under the neutral condition. The monomer emission, in contrast, is much higher than dimer emission at any concentrations of $\gamma-\mathrm{CD}$ at a

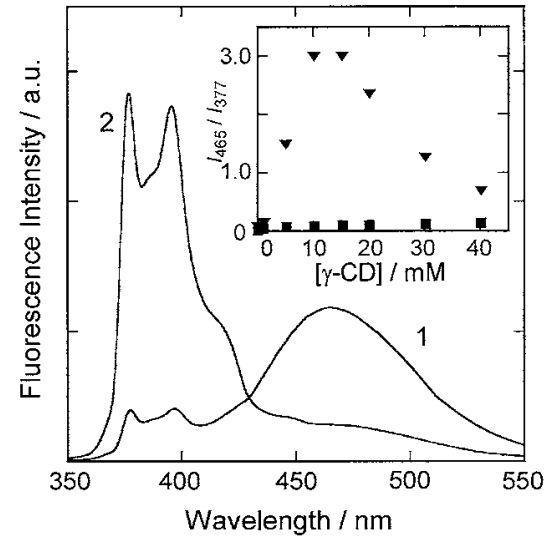

Fig. 6 Spectra of C1-APB with $15 \mathrm{mM} \gamma-\mathrm{CD}$ without saccharide at (1) $\mathrm{pH} 7.1$ and (2) $\mathrm{pH}$ 10.6. Inset: effect of the $\gamma$-CD concentration on $I_{465} / I_{377}$ at $\mathrm{pH} 7.1(\boldsymbol{\nabla})$ and $\mathrm{pH} 10.6(\mathbf{\square})$. [C1-APB] $=1.0 \times 10^{-6} \mathrm{M}$ in $2 \%$ DMSO-98\% water (v/v), $\mathrm{pH}$ at $25^{\circ} \mathrm{C}$ adjusted to 7.1 with 0.01 $\mathrm{M}$ phosphate buffer and to 10.6 with $0.01 \mathrm{M}$ sodium carbonate, $I=$ $0.1 \mathrm{M}$ with $\mathrm{NaCl}, \lambda_{\mathrm{ex}}=328 \mathrm{~nm}$.

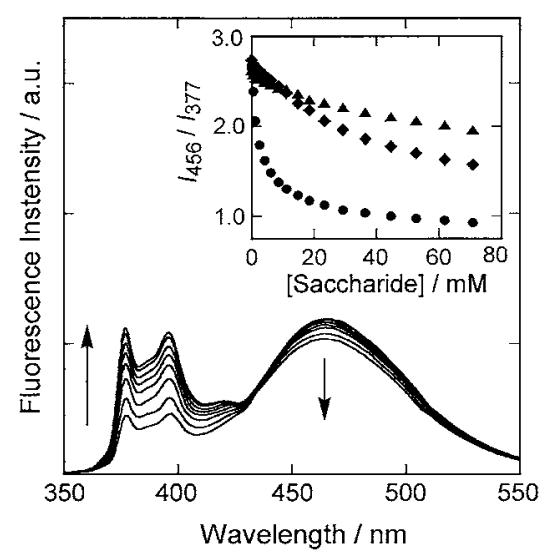

Fig. 7 Spectral changes of $\mathbf{C 1 - A P B} / \gamma-\mathrm{CD}$ upon the addition of Dfructose. Inset: changes in $I_{465} / I_{377}$ of $\mathbf{C 1 - A P B} / \gamma-\mathrm{CD}$ as a function of saccharide concentration at $\mathrm{pH}$ 7.1. D-Fructose $(\bullet)$, D-galactose $(\bullet)$ and D-glucose $(\mathbf{\Delta})$. $[\mathbf{C 1}$-APB $]=1.0 \times 10^{-6} \mathrm{M}$ in $2 \%$ DMSO-98\% water $(\mathrm{v} / \mathrm{v})$ containing $15.0 \mathrm{mM} \gamma-\mathrm{CD}, \mathrm{pH}$ at $25^{\circ} \mathrm{C}$ adjusted to 7.1 by $0.01 \mathrm{M}$ phosphate buffer, $I=0.1 \mathrm{M}$ with $\mathrm{NaCl}, \lambda_{\mathrm{ex}}=328 \mathrm{~nm}$.

basic $\mathrm{pH}$, indicating inhibition of the $2: 2$ (or 2:1) complex formation due to electrostatic repulsion of the two boronate anions.

Accordingly, the C1-APB $/ \gamma-\mathrm{CD}$ complex formed with $15 \mathrm{mM}$ $\gamma-\mathrm{CD}$ was used at neutral $\mathrm{pH}$ for the ratiometric sensing of saccharides. Figure 7 shows the ratiometric fluorescence spectral changes upon the addition of D-fructose. The corresponding changes upon the addition of D-glucose and 
D-galactose were also measured, and the $I_{465} / I_{377}$ results are shown in the inset of Fig. 7. The selectivity for D-fructose is evident. Although the results of selectivity were the same as those of the $\mathbf{C 1 - A P B} / \beta-C D$ complex, the ratiometric analysis is more useful than analysis by single monomer emission, because it compensates for any minor changes of the sample concentration and fluctuations in the lamp irradiation intensity. At present, however, the response mechanism includes the transfer of the C1-APB $/ \gamma$-CD complex from a 2:2 complex or a 2:1 complex (dimer) to a 1:1 complex (monomer), and PET mechanism, making a quantitative analysis difficult. To overcome this problem, the development of a non-PET type of pyrene probe is actively underway in our laboratory.

\section{Conclusions}

In this study, the inclusion complexes of a fluorescent phenylboronic acid (C1-APB) and four kinds of cyclodextrins (CDs) were compared by examining their $\mathrm{pH}$ profiles. Of these four CDs, $\beta-\mathrm{CD}$ was found to be the best host for C1-APB. The fluorescence quantum yield was greatly enhanced by the formation of a $\mathbf{C 1 - A P B} / \beta-\mathrm{CD}$ inclusion complex. The $\mathrm{pH}$ profiles of the $\mathbf{C 1 - A P B} / \beta-\mathrm{CD}$ complex exhibited increased fluorescence upon the addition of $\mathrm{D}$-fructose under neutral conditions. The C1-APB $/ \beta$-CD complex also exhibited increased fluorescence when various other saccharides were added, and the conditional binding constant was highest for Dfructose. The results are consistent with the known binding selectivity of phenylboronic acid. An examination of the $\beta$-CD concentration effect revealed the formation of a 1:1 inclusion complex of C1-APB and $\beta$-CD. The ratiometric approach was also evaluated for the $\mathbf{C 1 - A P B} / \gamma-\mathrm{CD}$ complex. High changes in the dimer emission response were obtained for the C1-APB/ $\gamma-\mathrm{CD}$ complex formed with $15 \mathrm{mM} \gamma-\mathrm{CD}$. Ratiometric fluorescence spectral changes were obtained upon the addition of saccharides, and changes in the intensity ratio of dimer and monomer emission revealed the selectivity for D-fructose. The selectivity results were the same as those of the C1-APB $/ \beta-\mathrm{CD}$ complex. This work demonstrates that different response systems for saccharide recognition are available by combining a simple probe (C1-APB) with various CDs.

\section{Acknowledgements}

This work was supported by Grants-in-Aid for Scientific Research from the Japan Society of Promotion of Science (18350043 and 19550130) and the Toray Scientific Foundation.

\section{References}

1. K. Anno and N. Seno, "Tokagaku-no-kiso (Fundamentals of Saccharide Chemistry, in Japanese)", 1984, Kodansha, Tokyo.

2. T. D. James, "Boronic Acids", ed. D. G. Hall, 2005, WileyVCH, Weinheim, 441.

3. M. D. Heagy, in "Glucose Sensing, Topics in Fluorescence Spectroscopy”, ed. C. D. Geddes and J. R. Lakowicz, 2006, Vol. 11, Springer, New York, 1.

4. J. P. Lorand and J. O. Edwards, J. Org. Chem., 1959, 24, 769.

5. J. Yoon and A. W. Czarnik, J. Am. Chem. Soc., 1992, 114, 5874.

6. H. Suenaga, M. Mikami, K. R. A. S. Sandanayake, and S. Shinkai, Tetrahedron Lett., 1995, 36, 4825.

7. N. DiCesare and J. R. Lakowicz, J. Phys. Chem. A, 2001, 105, 6834.

8. J. Yan, G. Springsteen, S. Deeter, and B. Wang, Tetrahedron, 2004, 60, 11205 .

9. H. Cao, T. McGill, and M. D. Heagy, J. Org. Chem., 2004, 69, 2959.

10. T. D. James, K. R. A. S. Sandanayake, R. Iguchi, and S. Shinkai, J. Am. Chem. Soc., 1995, 117, 8982.

11. W. Ni, G. Kaur, G. Springsteen, B. Wang, and S. Franzen, Bioorg. Chem., 2004, 32, 571.

12. G. Kaur, N. Lin, H. Fang, and B. Wang, in "Glucose Sensing, Topics in Fluorescence Spectroscopy”, ed. C. D. Geddes and J. R. Lakowicz, 2006, Vol. 11, Springer, New York, 377.

13. A. Yamauchi, Y. Sakashita, K. Hirose, T. Hayashita, and I. Suzuki, Chem. Commun., 2006, 4312.

14. I. Suzuki, A. Yamauchi, Y. Sakashita, K. Hirose, T. Miura, and T. Hayashita, Anal. Sci., 2007, 23, 1167.

15. A. Yamauchi, I. Suzuki and T. Hayashita, in "Glucose Sensing, Topics in Fluorescence Spectroscopy", ed. C. D. Geddes and J. R. Lakowicz, 2006, Vol. 11, Springer, New York, 237.

16. A.-J. Tong, A. Yamauchi, T. Hayashita, Z.-Y. Zhang, B. D. Smith, and N. Teramae, Anal. Chem., 2001, 73, 1530.

17. J. Szejtli, Chem. Rev., 1998, 98, 1743.

18. A. Yamauchi, T. Hayashita, S. Nishizawa, M. Watanabe, and N. Teramae, J. Am. Chem. Soc., 1999, 121, 2319.

19. A. Yamauchi, T. Hayashita, A. Kato, S. Nishizawa, M. Watanabe, and N. Teramae, Anal. Chem., 2000, 72, 5841.

20. R. Ozawa, T. Hayashita, T. Matsui, C. Nakayama, A. Yamauchi, and I. Suzuki, J. Inclusion Phenom. Macrocyclic Chem., in press.

21. R. Dhillon, C. J. Easton, S. F. Lincoln, and J. Papageorgiou, Aust. J. Chem., 1995, 48, 1117.

22. S. Hamai, J. Phys. Chem., 1989, 93, 2074.

23. S. Hamai, J. Phys. Chem., 1989, 93, 6527.

24. Y. Kanekiyo and H. Tao, Chem. Lett., 2005, 34, 196. 